\title{
Introduction
}

\author{
Jack E Henningfield
}

It gives me great pleasure and pride to introduce our concluding speaker, Dr Charles Robert Schuster. Dr Schuster was appointed Director of the National Institute on Drug Abuse (NIDA) in 1986, and he resigned voluntarily, as a birthday present to himself, in 1992. He is now a scientist, mentor, guru, ad hoc guidance counsellor and everything else with us at the Addiction Research Center, and I can't tell you what a pleasure it is to have him there.

Yesterday Frank Vocci said this field is working; we've come a long way from people quitting on their own at $2 \%$ annually. And the field has been working, in part, because of the efforts of Bob Schuster. He did the pivotal study in the 1960s that demonstrated the viability of nicotine replacement, one of the most widely cited studies in the basic litera- ture. His service on numerous committees of the Institute of Medicine, National Academy of Sciences and World Health Organisation have laid the groundwork for the criteria for evaluating addictions, and for evaluating medications.

And finally, as director of NIDA, I can tell you he was there at a time that the White House was anything but sympathetic to nicotine research, and he fought an uphill battle to sustain funding for nicotine research at the ARC, and in the extramural programmes. Perhaps his most truly courageous day was when Ron Davis and I met with him to discuss what would become of the addiction report because we knew it would have little credibility if NIDA would not back it in every way, and Bob Schuster, with unwavering support, backed and supported it.

\section{Research issues in smoking cessation}

\author{
Charles R Schuster
}

It was mentioned by Jack Henningfield that my career in tobacco research, which was very short-lived, occurred in the 1960 s. To start, I would like to review some of my early pharmacological research on cigarette smoking behaviour.

During the 1960s, it was not clear that cigarettes acted as a delivery device for the psychoactive substance nicotine. Rather, psychoanalytic theories of the aetiological basis of cigarette use stressed oral gratification. In order to look more closely at the pharmacological effect of nicotine on humans, five human subjects (referred to then simply as 'smokers'), all of whom were dependent on tobacco, were recruited for a study supported by the American Medical Association (Lucchesi, Schuster and Emley, 1967). ${ }^{1}$ Ben Lucchesi, a cardiovascular pharmacologist and physician, and I looked at what would happen over a 6-hour period to cigarette smoking frequency if smokers, who believed they were being studied for an unrelated purpose, were infused with nicotine.

Subjects were 21- to 30 -year-old male and female volunteers. They were studied for 15 consecutive days, and completed a 6-hour experimental session daily. A Y-adapter was used to infuse intravenously $0.9 \%$ sodium chloride continuously, and either nicotine bitartrate or saline solution, randomly. The subjects were unaware, at all times, of the order of infusion. Both the number of cigarettes consumed during each session and the weight of the unsmoked portion of the cigarettes was measured and recorded. Only subjects who were capable of tolerating a $4 \mathrm{mg} / \mathrm{h}$ dose of nicotine without subjective responses were included in this study.

It was found that Subject 1 smoked 17.9 cigarettes on average across seven sessions in a 6-h period, with very little variance, and a standard deviation of only 0.72 . The rest of the subjects showed the same type of regularity from session to session. As a matter of fact, Subject 2 smoked 7 cigarettes during every single one of the four sessions in which he received a saline infusion through an indwelling intravenous catheter.

When the subjects were infused with nicotine, at a rate of $2 \mathrm{mg}$ in the first hour and 4 $\mathrm{mg} / \mathrm{h}$ for the remaining $5 \mathrm{~h}$ of the 6 - $\mathrm{h}$ session, we saw a statistically significant, and I think biologically significant, decline in all five of the 
subjects. In addition, the subjects were informed that they had to place the unsmoked portion of their cigarettes (commonly referred to as the 'butt') into a special container for hygienic purposes. When these cigarette butts were weighed, it was found that the residual weight of the cigarettes that remained unsmoked was significantly greater when the subjects had been infused with nicotine.

Consequently, it was concluded that subjects who didn't know we were studying nicotine, and who were not able to distinguish between drug days and saline days, showed a significant decrease in both the number of cigarettes they smoked and the amount of each cigarette smoked. These data supported the contention that, at least in part, the reinforcing actions of smoked tobacco were based upon the psychoactive effects of nicotine.

More recently, it has been unequivocally demonstrated, with both human and animal models, that nicotine will serve as a reinforcer in the same way as other drugs of abuse. For example, Henningfield and his colleagues at the Addiction Research Center, investigated the reinforcing effects of intravenous nicotine in tobacco using human subjects by allowing them to self-administer nicotine through an IV catheter. $^{2}$ The results corroborated previous studies using squirrel monkeys and other animals, which had demonstrated that nicotine could serve as a positive reinforcer. In this study, rates of self-administration of nicotine were significantly higher than those of saline.

Nicotine has also been shown to produce mood changes and liking scores that are very similar to other drugs of abuse. ${ }^{3}$ Furthermore, Murray Jarvik and his colleagues ${ }^{4}$ clearly established that there is physical dependence on nicotine and a clear-cut nicotine withdrawal syndrome.

Based on all of the evidence, it is clear that nicotine use fits all the criteria for being labelled drug abuse. This conclusion has been given official status by the inclusion of tobacco dependence in the Diagnostic and Statistical Manual of Mental Disorders of the American Psychiatric Association, ${ }^{5}$ and the report of the US Surgeon General on nicotine addiction. ${ }^{6}$

The reason I have presented this historical background is to emphasise that we have come a very long way in terms of understanding the pharmacological basis of tobacco use and dependence. Although this fact is obvious to this audience, I think we need to step back and realise the remarkable progress that has been made in a relatively short period of time. On the other hand, I would contend that our understanding of some of the behavioural determinants of smoking has lagged behind.

The data presented yesterday, in which a large percentage of people who were given nicotine patches or nicotine gum continued to smoke, indicate that tobacco use cannot simply be conceived as a way of delivering nicotine to the brain. It has other behavioural significance, an understanding of which is essential to increasing the effectiveness of smoking prevention and treatment interventions.

Although I hate personal anecdotes, I hap- pen to be one of the people present who could truly qualify as a recovering tobacco addict. Over 20 years ago, which was around the time I quit smoking, I was hospitalised twice for lung problems caused by smoking. I was strongly advised by physicians to stop smoking, but to no avail. For three years, I was a conflicted, troubled, and unhealthy cigarette smoker. Part of the reason for my inability to stop smoking was my belief that it would be impossible for me to sit down and write without having a cigarette. As a professor and researcher, writing was essential to my career.

I would like to take my own personal experience and translate it into behaviour analytical terms. The smoking of cigarettes is not incompatible with other behaviours and, therefore, can become part of behavioural sequences. Smoking fills in time. It also may be seriously influenced by the status of other concurrent behaviours and reinforcement schedules, such as maintaining the behaviour of sitting at a computer terminal when ideas are not flowing. These hypotheses are based on the excellent animal research that has occurred over the last 20 years by Dr John Falk, that has not dealt with nicotine or tobacco, per se, but is very relevant to this issue.

In analysing the conditions under which I smoked, it became obvious that to a great extent my cigarette smoking behaviour was what Falk has called 'adjunctive'. ${ }^{7}$ Adjunctive behaviour is maintained by a weak reinforcer, but occurs at excessively high rates because of contextual determinants. Falk's (1961) original observations of adjunctive behaviour occurred in laboratory experiments in which rats, who were given small quantities of food on an intermittent time basis, consumed huge quantities of water - up to $50 \%$ of their body weight in a period of only 1-2 hours. If water was not available but a running wheel was, they ran excessively. I submit to you that, under the same circumstances, if these rats had had a pack of cigarettes and could have lit one, they would have smoked excessively.

The reasoning behind this conclusion is that these types of lean reinforcement schedules generate this type of adjunctive behaviour, much in the same way as writing for me was a lean reinforcement schedule, with smoking as an essential ingredient in that activity. It is important to recognise the behavioural significance of the use of tobacco that supersedes its pharmacology, and I vehemently suggest that more intensive research needs to be done in this area.

I would also like to make a comment about the term 'contingencies'. What is meant by contingencies? Basically - and I'll put it the way Joe Brady, my mentor, would - if you want people to behave the way you want them to behave, then you've got to give them something for doing it. This concept applies all the way across the board, whether it's the therapist who is involved in the treatment, or the patient who is trying to stop using cigarettes, or the family members who have to put up with the irritation and the general poor mood of those who are trying to give up 
cigarettes. No matter where you look in this situation, you've got to think about how to structure the contingencies to promote the initiation and maintenance of the desired behaviours. It has been suggested by Ken Warner that people who are dependent on tobacco should pay for their own therapy. This may make sense from an economic viewpoint since the decrease in the expenditure for tobacco following cessation would quickly pay for the therapy. But where are the contingencies for remaining abstinent? The immediate economic benefit from cessation is now delayed while the health benefits from cessation of smoking are always very delayed. What exactly, then, would promote the initiation and maintenance of smoking cessation?

Perhaps the answer lies in adapting some of the techniques that have been used in the treatment of other forms of addictive disorders. For example, in reciprocal couples counselling, significant others are used to provide immediate and on-going reinforcement of the patient's behaviour of abstaining from alcohol or drugs. ${ }^{9}$

If the contingencies cannot be arranged so that there is immediate payoff for the behaviour of an individual, then it will be difficult to maintain that behaviour. This process gets even more complicated when individuals lack alternative reinforcers, either because they are economically and socially disadvantaged or because they suffer from co-morbidity, that is, other types of psychiatric disorders, and delivery of effective reinforcers for behaviour change may be hindered.

In the area of heroin addiction, for example, many of the clients who present for treatment show symptoms of major depression. Treatment programmes for heroin addiction may be unsuccessful unless the psychological and behavioural problems, such as depression, are addressed concurrently with the addiction problem. I believe this concurrent treatment pattern is necessary for success, whether addressing heroin addiction or cigarette smoking.

Why is it that depression is associated with using heroin to a great extent, or with high rates of tobacco use? I don't think we know. It is possible that there is some symptomatic relief of the depression by these agents, or that depression, by definition, means there is a lack of alternative reinforcers. Perhaps there isn't much that 'turns them on' in the world, and drugs remain one of the few things out of which they can get something. More research is needed in this area.

Economic influences on tobacco consumption have been demonstrated by longitudinal studies undertaken in the UK from 1979 to 1991 that found that, as the price of tobacco went up, the consumption per person went down. Although this is an expected outcome, it is important to note that these kinds of experiments are never clean, because what drove the price up might also have been an anti-smoking attitude that gave rise to higher taxes. It is difficult to say clearly that it was the increase in the price alone that lead to decreased consumption. Nevertheless, this type of relationship does certainly give credence to the comment that Ken Warner made that we should be writing to our legislators to get increases in taxes so we increase the price of tobacco.

Economic principles can also be used to analyse the behaviour of individual subjects. Warren Bickel and his colleagues ${ }^{10}$ recruited human subjects who were dependent upon tobacco. These subjects all had Fagerström scale scores of six, seven, or eight, or high enough that they would qualify as tobacco dependent. The subjects were told that they were going to have to pull on a lever a certain number of times in exchange for either one puff, two puffs, or four puffs on their favourite cigarette. The subjects worked for $3 \mathrm{~h}$, and could pull on the lever as frequently as they wanted. The schedule was varied. Some days they had to pull it 200 times to get one puff, on other days 400 times for two puffs, and so forth, all the way up to 1600 times. Those of you who are acquainted with economics will recognise that these numbers are equivalent to the unit price; that is, the increases in response requirements equal increases in price. Consequently, different unit prices are represented. When the effect of unit price on cigarette consumption or the number of puffs was analysed, a positively decelerating demand curve resulted for all five subjects.

I think it is important to understand that the behaviour of cigarette smoking is lawful on both an individual basis and a societal basis, and that it responds to contingency changes, such as increases in price in both contexts. It is also interesting to look at the effect on the elasticity of this demand curve when alternative reinforcers available at a lower price are introduced. Dr Warren Bickel, in Vermont, has found that alternative reinforcers available at a lower price increase the elasticity of the demand curve or, in other words, the curve drops off at lower cigarette unit prices. ${ }^{10}$

A very exciting possibility would be to look at the effects of nicotine patches in interaction with alternative reinforcers; that is, to combine both the behavioural and pharmacological interventions, and evaluate the resultant decrease in the value of cigarette puffs. This approach holds great promise for a more realistic goal regarding treatment of cigarette smoking because the expectation is to decrease the value of cigarettes, which is a more realistic approach than previous attempts to stop cigarette consumption completely, based on evaluation of new behavioural or pharmacological interventions.

This behavioural economic analysis that has been developed by Warren Bickel and his colleagues at the University of Vermont has given us a very clear-cut way of looking at the value of nicotine replacement therapy. ${ }^{10}$ The behavioural economic approach is one that I recommend to other researchers in the field.

I would like to turn to an entirely different issue, the issue of prevention. According to the 30-day cigarette consumption data from the 1990 National Household Survey on Drug 
Abuse,${ }^{11}$ individuals who have less than a high school education show a much higher prevalence of cigarette smoking than individuals who are college graduates. A similar relationship exists for employment status. Among the full-time employed, smoking has a prevalence of around $30 \%$; among the unemployed, it's well over $40 \%$. Therefore, both employment and education have a great influence on cigarette consumption.

I think this holds important implications in terms of our prevention interventions. The efficacy of these interventions may depend upon sufficient affluence to have access to alternative reinforcers. Lifestyle change recommendations such as going to a gym or other places that provide alternative types of activities to cigarette smoking are only appropriate for those individuals who are affluent enough to afford to go to gyms, or who live in communities where these alternatives are available. We must look at this challenge in terms of disadvantaged neighbourhoods. Note I say neighbourhoods rather than ethnic or minority groups. Our recent paper in $\mathcal{F} A M A^{12}$ clearly shows that when you control for neighbourhoods, activities like crack cocaine smoking, (thought to be about twice as prevalent in African-Americans as it is in whites), are related to neighbourhood, and racial and ethnic differences disappear. Consequently, I'm talking about disadvantaged neighbourhoods, not necessarily about disadvantaged groups.

We must develop strategies for coping with the inherent problems in these disadvantaged neighbourhoods that arise not only from the lack of alternative reinforcers, but also from the hopelessness and helplessness that is felt by people. People in disadvantaged neighbourhoods do not believe, the way that others do, that they have a rosy and bright future to look forward to, something to live for. I would submit that our prevention interventions are not going to be effective unless we take these neighbourhood problems into account.

It is also very important in terms of ongoing research to take note of what I am calling the 'degentrification of drug use' in this country, and begin to address seriously the neighbourhood variables and the community variables that are responsible for generating, not only cigarette smoking, but crack cocaine use and all of the other substance abuse disorders that pervade those neighbourhoods.

In children, it is well established that cigarette use is an important gateway drug. ${ }^{13,14}$
I would recommend that prevention programmes become more global in their approach, and that alcohol, tobacco, and substance abuse should be viewed as interdependent, and not separate issues, because I don't think they can be disentangled. I think that the variables that are responsible for the high prevalence rates and incidence of all of these forms of substance use are the same.

Finally, I would say that in order to obtain effective prevention, it is essential that we involve and unify all of the elements that make up a community, rather than trying to involve specific community organisations, such as schools, churches, businesses, and parents and that is hard work. But I would submit that all of the research we have done on substance abuse prevention will be ineffective unless we can incorporate all of the agencies in the community so the children are receiving a unified and consistent 24-hour-a-day message from all aspects of the community.

1 Lucchesi BR, Schuster CR, Emley GS. The role of nicotine as a determinant of cigarette smoking frequency in man with observations of certain cardiovascular effects associated with the tobacco alkaloid. Clin Pharmacol Therapeut $1967 ; 8$ : 789-96.

2 Henningfield JE, Miyasato K, Jasinski DR. Cigarette smokers self-administer intravenous nicotine. Pharmacol Biochem Behav 1983; 19: 887-90.

Biochem Behav 1983; 19: 887-90.
3 Henningfield JE, Miyasato K, Jasinski DR. Abuse liability and pharmacodynamic characteristics of intravenous and
inhaled nicotine. F Pharmacol Exp Therapeut 1985; 234: $1-12$.

4 Shiffman SM, Jarvik ME. Smoking withdrawal symptoms in two weeks of abstinence. Psychopharmacology 1976; 50: 35-9.

5 American Psychiatric Association. Diagnostic and statistical manual of mental disorders, $3 r d$ edn. Washington, DC: American Psychiatric Association, 1987.

6 US Office on Smoking and Health. The health consequences of smoking: nicotine addition: A report of the Surgeon General, 1988. Washington, DC: US Government Print

7 Falk JL. Drug dependence: myth or motive? Pharmacol Biochem Behav 1983; 19: 385-91.

8 Falk JL. Production of polydipsia in normal rats by an intermittent food schedule. Science 1961 ; 133: 195-6.

9 Higgins ST, Delaney DD, Budney AJ, Bickel WK, Hughes Jr FF, Fenwick JW. A behavioral approach to achieving initial cocaine abstinence. Am f Psychiatry 1991; 148: 1218-24

10 Bickel WK, DeGrandpre RJ, Hughes JR, Higgins ST. Behavioural economics of drug self-administration. II. A unit-price analysis of cigarette smoking. $\mathcal{F}$ Exp Anal Behav 1991; 55: 145-54.

11 National Institute on Drug Abuse. National Household Survey on Drug Abuse: Main Findings, 1990. Rockville, MD: US Government Printing Office. (DHHS Publication No (ADM) 91-1788.)

12 Lillie-Blanton M, Anthony JC, Schuster CR. Probing the meaning of racial/ethnic group comparisons in crack meaning of racial/ethnic group compariso

$13 \mathrm{Kandel} \mathrm{D}$. Stages in adolescent involvement in drug use. Science $1975 ; 190: 912-4$.
S

14 Henningfield JE, Clayton R, Pollin W. Involvement of tobacco in alcoholism and illicit drug use. $\mathrm{Br} \mathcal{F}$ Addict 1990; 85: 279-92. 